\title{
BMJ Open Searching for the erosion of empathy in medical undergraduate students: a longitudinal study
}

\author{
José Manuel Blanco, ${ }^{1,2}$ Fernando Caballero, ${ }^{1}$ Santiago Álvarez, ${ }^{1}$ Mercedes Plans, ${ }^{2}$ \\ Diana Monge (D) ${ }^{1}$
}

To cite: Blanco JM, Caballero F, Álvarez S, et al. Searching for the erosion of empathy in medical undergraduate students: a longitudinal study. BMJ Open 2020;10:e041810. doi:10.1136/ bmjopen-2020-041810

- Prepublication history for this paper is available online. To view these files, please visit the journal online (http://dx.doi org/10.1136/bmjopen-2020041810).

Received 07 July 2020 Revised 04 December 2020 Accepted 08 December 2020

Check for updates

(C) Author(s) (or their employer(s)) 2020. Re-use permitted under CC BY-NC. No commercial re-use. See rights and permissions. Published by BMJ.

${ }^{1}$ School of Medicine, Universidad Francisco de Vitoria, Madrid,

Spain

${ }^{2}$ Valle de la Oliva Healthcare Centre, Madrid, Spain

Correspondence to

Dr Diana Monge;

d.monge@ufv.es

\section{ABSTRACT}

Objective To analyse the trajectory of empathy throughout the degree programme of medicine in a Spanish school of medicine.

Design Longitudinal, prospective 5-year study, between October 2014 and June 2019.

Setting Students from a Spanish university of medicine. Participants Two voluntary cohorts of undergraduate medical students from two different school years were invited to participate $(\mathrm{n}=135$ (cohort 1, $\mathrm{C1}$ ) and 106 (cohort 2, C2) per school year). Finally, a total number of 174 students (102 (C1, 71.6\% women) and 72 (C2, 70.8\% women) students, respectively) were monitored for 5 years. Each cohort was divided in two subcohorts of paired and unpaired students that were analysed to check possible social desirability bias.

Primary outcome measure The Jefferson Scale of Empathy (JSE).

Results The cohort of 102 students (C1) monitored between their first and fifth years of study (71.6\% women) showed an improvement among paired women of 2.15 points in total JSE score $(p=0.01)$ and 2.39 points in cognitive empathy $(p=0.01)$; in the unpaired female cohort the increase was of 2.32 points (cognitive empathy) $(p=0.02)$. The cohort of 72 students (C2) monitored between their second and sixth years of study $(70.8 \%$ women) displayed a cognitive empathy increase of 2.32 points $(p=0.04)$ in the paired group of women. There were no significant differences between paired and unpaired results for either cohort. Empathy scores among men did not decrease.

Conclusions The empathy of medical students at our school did not decline along grade years. In fact, it improved slightly, particularly cognitive empathy, among women. This paper contributes to enlarge data from Europe, where longitudinal studies are scarce. It supports the idea that there may be global geo-sociocultural differences; however, more studies comparing different school settings are needed.

\section{INTRODUCTION}

Empathy is important for a clinical relationship and it is beneficial both for the patient and the healthcare professional. In patients, it has been associated with greater levels of satisfaction, ${ }^{1-3}$ greater participation in decisionmaking and caring for their health ${ }^{4}$; greater

\section{Strengths and limitations of this study}

This is a longitudinal study of two different cohorts we tracked yearly for 5 years.

- We used a Spanish-validated version of Jefferson Scale of Empathy that is the most widely used for measuring medical empathy.

- We compared the results between paired and unpaired student cohorts to control the social desirability bias.

- Our students follow a person-centred medicine project in addition to their medical technical training.

- Our study includes only one university.

adherence to treatment, ${ }^{156}$ a better quality of life, lower levels of stress ${ }^{1}$ and improved health results. ${ }^{78}$ Regarding the physician, empathy has been linked to better communication and relationships with the patient, ${ }^{9}$ improved clinical skills, ${ }^{9-11}$ stronger capacity for interprofessional collaborative work, ${ }^{12}$ higher level of satisfaction and well-being, ${ }^{13}{ }^{14}$ lower levels of professional burnout, ${ }^{15-17}$ less substance abuse or attempted suicide, ${ }^{18}$ greater ethical awareness ${ }^{19}$ and a reduction in the number of official complaints. ${ }^{2021}$ Moreover, different authors have reported that medical students with greater empathy have a higher level of well-being $^{22}$ and experience less burnout. ${ }^{23}$ Students with greater empathy achieve higher practical work assessment scores from teachers or simulated patients. ${ }^{24}$

Since Hojat $e t a l$ 's study in $2009,{ }^{26}$ several new studies have pointed out a decline in empathy trajectory among schools. ${ }^{27} 28 \mathrm{~A}$ systematic review of qualitative and quantitative studies (1990-2010) supported this observation which was mainly studied from longitudinal designs. ${ }^{29} \mathrm{~A}$ recent nationwide, multi-institutional, cross-sectional study from the USA comparing preclinical and clinical data found a decline in empathy scores. ${ }^{30}$

In 2015 , Roff ${ }^{31}$ warned about the possibility that empathy of medical students could not 
decline over time, at least, significantly. She conducted a literature review of cohorts of medical students monitored with the student version of the Jefferson Scale of Empathy (JSE-S) in Japan, South Korea, China, Kuwait, India, Iran, UK, the USA, Australia, Brazil, Colombia, the Dominican Republic and Portugal. ${ }^{31}$ A subsequent scoping review of English, Spanish, Portuguese and French literature (2009-2016) published in 2017 revealed that the predominant trend in cross-sectional studies was of a significantly higher or of similar empathy scores across years. Nevertheless, most longitudinal studies presented either mixed results or empathy decline. The authors of this study believe that the literature does not offer clear conclusions relative to changes in student empathy. ${ }^{32}$

In 2019, a meta-analysis was published to synthesise existing evidence examining how empathy changes during undergraduate medical education assessing whether different types of measures produce different results. Spatoula et $a l^{33}$ discovered that studies showed contradictory results. For example, studies in the USA found a significant reduction in empathy, but other countries, such as Portugal and Brazil did not show the same trend, maintaining the empathic disposition throughout medical school. The authors also stated that the JSE report had higher effect sizes, considering that the decrease in empathy may depend on how empathy is measured. ${ }^{33}$

We do not know whether most data that come from the USA are generalisable and whether empathy trajectory could be a global problem or not. It has relevant practical academic consequences. We aimed to ascertain if empathy skills in Spain should be enhanced. More data from certain areas of the world, such as Europe, are needed since geo-sociocultural settings appear to exert an influence. ${ }^{34}$ More longitudinal data may provide a wider perspective about this topic and may help us to make educational decisions. ${ }^{33}$

In summary, although empathy is considered a basic skill for medical education and one would expect that medical students would become more empathetic as they progress through their career, results about its trajectory are contradictory. ${ }^{33}$ There are Spanish studies that have validated versions of JSE. ${ }^{35-37}$ However, these studies are cross-sectional and do not analyse the trajectory of empathy throughout time in different student cohorts. Nevertheless, the JSE seems to be a good resource to derive knowledge about empathy trajectory in Spain.

Another aspect to take into account is the social desirability bias described by Edwards ${ }^{38}$ when answering self-completed questionnaires. The authors of the JSE recommend that the questionnaire should be anonymous and applied in non-penalising situations. Some studies $^{39}{ }^{40}$ have controlled for this effect on JSE scores, not observing substantial changes in them. Nevertheless, the risk of giving fake positive answers and trying to present a socially acceptable image can always be present.

The objective of this study is to measure the trajectory of medical students' levels of empathy at a Spanish university. We tracked two different cohorts to obtain a wider sample and checked the consistency of our outcomes by following up two different classes of undergraduates. We also compared the scale results within paired student cohorts to know if voluntary personal identification by means of a numerical code could introduce a social desirability bias.

\section{METHODS \\ Design}

This was a longitudinal prospective cohort study.

\section{Educational background}

Since its inception, our school has been part of the professional group known as The International Network for Person-Centered Medicine. ${ }^{41}$ One of its objectives is the maintenance and enhancement of levels of student empathy. Our person-centred curriculum has the following 6-year educational pillars: a medical humanities pathway (one subject per year, from first to fourth years, coping with disciplines such as epistemology, anthropology, ethics, deontology and history of medicine), and a standardised patient-simulation programme on clinical communication and relationship.

During the first year and the second year, students take part in a programme of early clinical immersion. It consists of a clinical placement totalling 4 days at the health centre (primary care) and 4 days in hospital during the first year. On the second year, they attend 2 days at a palliative care unit, 3 days in a psychiatric centre, and again, 3 days in a health centre. It provides students direct experience of the real medical practice in different contexts. Afterwards, they reflect on six principal areas: the patient-physician relationship (professional attitudes and behaviour), communication, the participation of patients and their families in care and decision-making, teamwork, healthcare organisation and teaching. The work concludes with their writing a report summarising their reflections. During their clinical years, from third to sixth year, students approach different clinical-simulated scenarios and perform their internship with tasks pointed out and recorded within an electronic portfolio.

\section{Measurement instrument}

\section{The JSE}

The most widely used measure of medical empathy is JSE. It is designed specifically to measure self-perceived empathy in doctor-patient relationship, and it is more sensitive to changes than others. ${ }^{42}$ The International Roughness Index (IRI) is a generic measure of empathy and the JSE measures empathy specifically for healthcare professionals. Both scales measure different but related constructs. $^{43}$

This study used the JSE, in its professional version (JSEHP), duly translated, adapted and validated for our environment. ${ }^{37}$ The JSE-HP can be used to assess the empathy of medical students who have already had contact with real or simulated patients (commonly from the third 

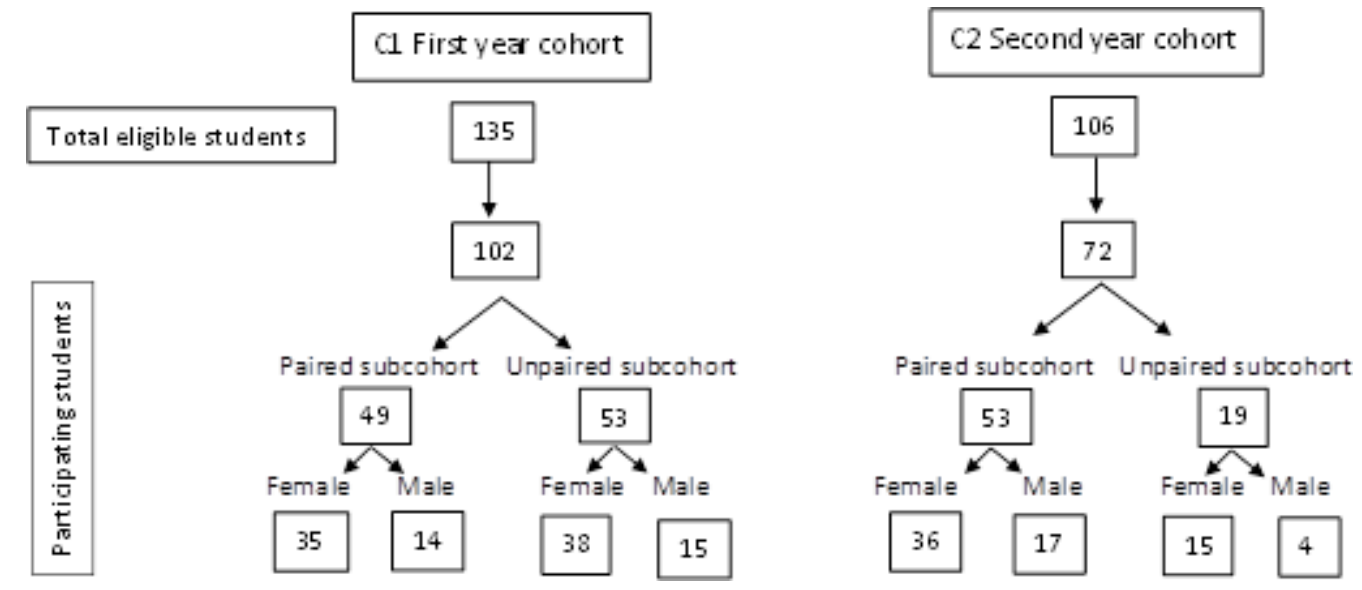

Figure 1 Cohorts description: sample size of $\mathrm{C} 1$ from first year and $\mathrm{C} 2$ from second year. $\mathrm{C} 1$, cohort 1; $\mathrm{C} 2$, cohort 2.

year). ${ }^{44} 45$ In our case, we decided to use this version because our students take part in the programme of early clinical immersion (see above) which allows them to view themselves from the physician's perspective.

The JSE-HP has 20 items and is scored on a 7-point Likert Scale ( $1=$ totally disagree, $7=$ totally agree). The possible scores range from 20 to 140 points, so the highest scores are associated with a greater degree of empathy. Although there is no time limit for the assessment, it is usually answered in less than $5 \mathrm{~min}$. After the factorial analysis, ${ }^{45}$ three dimensions are: dimension 1 : patient perspective taking (cognitive aspects of empathy) made up of 10 items; dimension 2: compassionate care (emotional aspects of empathy) consisting of 8 items; dimension 3: standing in the patient's shoes containing 2 items.

\section{Setting and participants}

The study took place between October 2014 and June 2019 in the School of Medicine of Francisco de Vitoria University (UFV). Two cohorts, cohort 1 (C1) and cohort 2 (C2) of students (figure 1), respectively, from the first and the second years (academic year 2014-2015), were monitored for 5 years as they were the first cohorts to follow all the person-centred curriculum as it is now. Each student received a call to participate voluntarily in the study, at the beginning of the class and fill in the paper questionnaire. It was administered in a classroom setting. The degree of empathy within C1 was evaluated at the start of the medical degree and at the end of the second, fourth and fifth years. The C2 completed the JSE-HP at the start of the second year, and at the end of the third, fifth and sixth years.

To control the desirability bias, the two cohorts were subdivided into two subcohorts, one consisting of numerical code identified students (paired) and another of unidentified students (unpaired). So, the paired cohort could be tracked within subject longitudinally and compared.

\section{Patient and public involvement}

No patient was involved.

\section{Statistical analysis}

The quantitative variables (JSE total, dimensions 1, 2 and $3)$ are presented with their mean and SD. The qualitative variables (sex, code, cohort year) are presented with their frequency and percentage. The mean comparison of the JSE results in the paired student cohorts, when the variables showed a non-gaussian distribution in the comparison groups, was made using the Friedman nonparametric test. The mean comparison of the JSE results in unpaired student cohorts was made using the KruskalWallis non-parametric test.

The SPSS V.21.0 statistics program was used for statistical analysis, with a significance level of $p<0.05$ in all the analyses.

\section{RESULTS}

C1 initially had 135 students, and 102 of them $(75.5 \%$ of this class) were voluntary monitored for the 5 years, from their first year of career until their fifth year. It comprised 73 women $(71.6 \%)$ and 29 men $(28.4 \%)$. The C2 students initially account for 106 participants and $72(67.9 \%$ of this class) completed their voluntary monitoring from their second year until the end of their sixth year. It comprised 51 women $(70.8 \%)$ and 21 men $(29.2 \%)$.

Given that the personal identification by means of a code was voluntary, both cohorts were subdivided into two subcohorts, one consisting of numerical code identified students (paired) and another of unidentified students (unpaired). In C1, 49 students were identified by code (48\%): 35 women $(71.4 \%)$ and 14 men (28.6\%). Fifty-three students remained unidentified (52\%): 38 women $(71.7 \%)$ and 15 men $(28.3 \%)$. In the C2, 53 students were identified by numerical code $(73.6 \%): 36$ women $(67.9 \%)$ and 17 men $(32.1 \%)$. Nineteen students remained unidentified (26.4\%): 15 women $(78.9 \%)$ and 4 men $(21.1 \%)$.

In the first clinical years (fourth cohort year), we observe a slight drop in the total JSE score in both cohorts. However, scores at the end of follow-up recover 


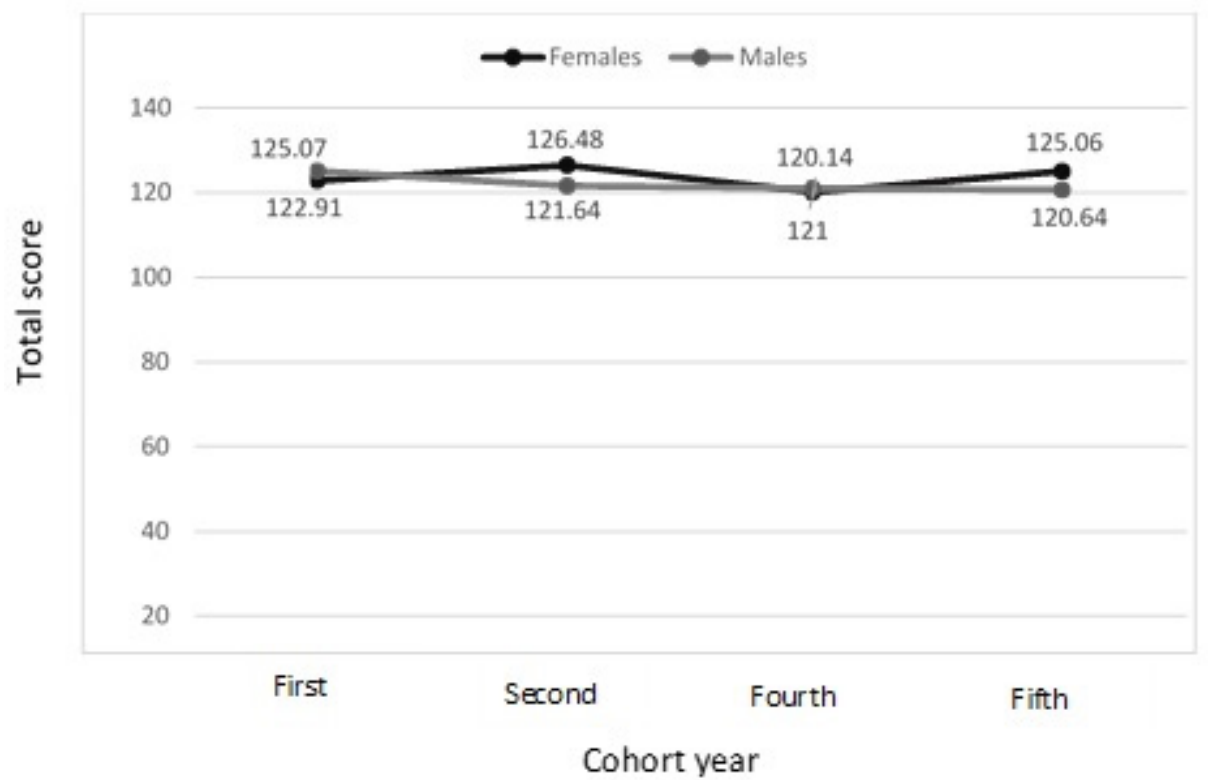

Figure 2 JSE-HP results in C1 paired cohort of 35 women and 14 men monitored for 5 years (start of first academic year-end of fifth year). C1, cohort 1; JSE-HP, Jefferson scale of empathy-professional version.

to baseline levels. In C2 they even improve slightly (see figures 2 and 3 ).

In the paired female C1 students, a statistically significant increase in global empathy (JSE-HP total) of 2.15 points (Cohen's d 0.26) was observed from their first to their fifth year $(\mathrm{p}=0.01)$ (figure 2$)$. In the same way, the cognitive empathy (dimension 1 JSE-HP) increased 2.39 points (Cohen's d 0.35) when finishing the fifth year compared with the first $(\mathrm{p}=0.01)$ (see table 1$)$.

In the unpaired women of this cohort, an improvement in cognitive empathy (dimension 1 JSE-HP) was also observed of 2.32 points (Cohen's d 0.48) ( $\mathrm{p}=0.02$ ). Differences found in empathy scores along time and between paired and non-paired students were not statistically significant (table 1).

In the paired C2, an increase in cognitive empathy (dimension 1 JSE-HP) was observed in women of 2.33 points (Cohen's d 0.44) $(\mathrm{p}=0.04)$. Again, there were no statistically significant differences along time and between paired versus non-paired students (table 2).

As can be seen in tables 1 and 2 and figures 2 and 3, male cohorts showed levels of empathy that did not fall significantly among the preclinical (first and second years) and clinical years (third to sixth years).

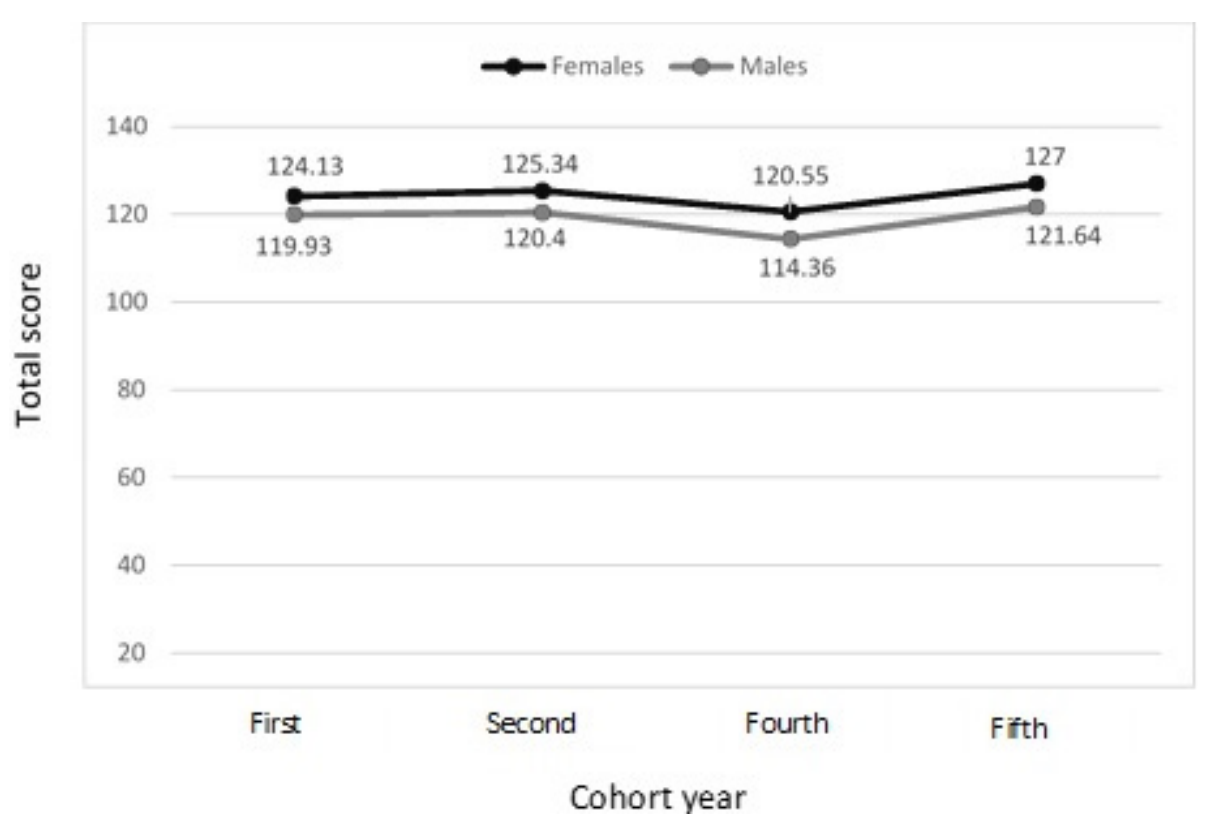

Figure 3 JSE-HP results in C2 paired cohort of 36 women and 17 men monitored for 5 years (start of second academic yearend of sixth year). C2, cohort 2; JSE-HP, jefferson scale of empathy-professional version. 
Table 1 JSE-HP results in C1 of medical students at the UFV monitored from the first to fifth years (paired and unpaired)

\begin{tabular}{|c|c|c|c|c|c|}
\hline Year & $\begin{array}{l}2014 / 2015 \\
\text { First (mean, SD) }\end{array}$ & $\begin{array}{l}2015 / 2016 \\
\text { Second (mean, SD) }\end{array}$ & $\begin{array}{l}2017 / 2018 \\
\text { Fourth (mean, SD) }\end{array}$ & $\begin{array}{l}2018 / 2019 \\
\text { Fifth (mean, SD) }\end{array}$ & $P$ value \\
\hline Paired women (n, \%) & $35(71.4)$ & $33(70.2)$ & $35(71.4)$ & $33(70.2)$ & \\
\hline $\operatorname{Dim} 2$ & $48.74(4.62)$ & $50.00(4.51)$ & $48.37(5.04)$ & $49.33(4.94)$ & 0.45 \\
\hline $\operatorname{Dim} 3$ & $12.77(1.14)$ & $12.00(1.78)$ & $11.63(2.22)$ & $11.94(1.69)$ & 0.25 \\
\hline Dim 1 & $64.29(3.20)$ & $61.86(7.16)$ & $61.36(7.40)$ & $61.71(6.59)$ & 0.75 \\
\hline Dim 2 & $48.43(4.31)$ & $48.64(5.55)$ & $48.43(7.25)$ & $47.36(8.87)$ & 0.78 \\
\hline Dim 3 & $12.36(1.28)$ & $11.14(2.14)$ & $11.21(2.81)$ & $11.57(2.62)$ & 0.44 \\
\hline JSE total & $125.07(6.89)$ & $121.64(12.00)$ & $121.00(14.57)$ & 120.64 (16.78) & 0.37 \\
\hline Dim 3 & $12.03(1.91)$ & $12.11(1.61)$ & $11.55(2.28)$ & $11.39(2.54)$ & 0.77 \\
\hline JSE total & $124.13(10.70)$ & $125.34(10.24)$ & 120.55 (11.37) & $127.00(8.58)$ & 0.10 \\
\hline Unpaired men (n, \%) & $15(28.3)$ & $15(28.3)$ & $11(33.3)$ & $11(28.2)$ & \\
\hline Dim 1 & $60.07(6.13)$ & $60.20(7.28)$ & $57.00(10.25)$ & $60.73(6.87)$ & 0.79 \\
\hline Dim 2 & $47.33(4.82)$ & $48.47(5.14)$ & $45.18(6.43)$ & $49.55(4.82)$ & 0.30 \\
\hline Dim 3 & $12.53(2.20)$ & $11.73(1.75)$ & $12.18(1.66)$ & $11.36(2.73)$ & 0.31 \\
\hline JSE total & $119.93(10.43)$ & $120.40(12.03)$ & $114.36(16.10)$ & $121.64(11.59)$ & 0.59 \\
\hline
\end{tabular}

C1, cohort 1; Dim, dimension; JSE-HP, jefferson scale of empathy-professional version; UFV, francisco de vitoria university.

\section{DISCUSSION}

The current study describes the curricular trajectory of empathy in medical students at a university in a European setting. The empathy of medical students at the UFV did not show a decline of scores on the JSE-HP at the end of their studies compared with their results when they started (preclinical and clinical courses, respectively). Moreover, it pointed out an increase of empathy trajectory in women, as evidenced by a slight improvement of cognitive dimension.

The JSE-HP measures self-perception of empathic attitudes but not empathic behaviour, though different studies have established a link between their results and those observed by the real ${ }^{464}$ or simulated patients. ${ }^{48}$ Otherwise, the cognitive empathy (dimension 1 JSE-HP) seems to be the most likely influenced through suitable educational programmes, ${ }^{49}$ since emotional empathy appears to be more innate. ${ }^{49}$

The samples correspond to a single non-profit private university in Madrid and may not be representative of the rest of the schools of medicine in our environment. The cohorts of identified students behaved in the same way as those who did not wish to be identified, which is similar to the observations made by Hojat et $a l .{ }^{26}$ This fact is interesting as it seems to limit the social desirability bias which may accompany self-administered questionnaires.
In Spain, there are no studies which analyse the degree of empathy of medical students over the long term. The current study is the first longitudinal work that provides a prospective monitoring of cohorts for 5 years. More longitudinal studies are required, as well as the effectiveness of the different programmes which aim to maintain and enhance it. Currently, we are carrying out an investigation which aims to analyse the degree of empathy in students across the eight medical faculties in Madrid (public and private) at three critical times in their training: at the start of the degree, at the end of the third year and at the end of the sixth. The analysis of this data will provide more evidence regarding the trajectory of empathy of Spanish medical students, discovering if differences exist in the empathy of students who take part in different curricular programmes, as well as establishing a proposal for cut-off values of low, medium and high levels of empathy in our environment.

The broader question is what is taking place globally. This study adds some evidence about the situation in Europe, where these kinds of studies are scarce, needed ${ }^{29}$ and under development. ${ }^{50}$ If we take into consideration Western European quality studies selected in the Spatoula et al's meta-analysis, ${ }^{33}$ nine cross-sectional and only three longitudinal, we find that they gathered and analysed data (difference in means and 95\% CI) from 
Table 2 JSE-HP results in C2 of medical students at the UFV monitored from the second to sixth years (paired and unpaired)

\begin{tabular}{|c|c|c|c|c|c|}
\hline Year & $\begin{array}{l}2014 / 2015 \\
\text { Second (mean, SD) }\end{array}$ & $\begin{array}{l}\text { 2015/2016 } \\
\text { Third (mean, SD) }\end{array}$ & $\begin{array}{l}2017 / 2018 \\
\text { Fifth (mean, SD) }\end{array}$ & $\begin{array}{l}2018 / 2019 \\
\text { Sixth (mean, SD) }\end{array}$ & $P$ value \\
\hline Paired women (n, \%) & $36(67.9)$ & 36 (67.9) & $36(67.9)$ & $29(64.4)$ & \\
\hline $\operatorname{Dim} 1$ & $61.81(6.32)$ & $61.81(5.98)$ & $63.69(4.90)$ & $64.14(4.02)$ & 0.04 \\
\hline Dim 2 & $49.17(5.27)$ & $49.94(4.34)$ & $50.53(4.00)$ & $50.52(4.59)$ & 0.09 \\
\hline Dim 3 & $11.472 .22)$ & $12.06(2.32)$ & $11.81(1.95)$ & $12.41(2.06)$ & 0.08 \\
\hline JSE total & $122.44(11.33)$ & $123.81(8.28)$ & $126.03(6.95)$ & $127.07(7.63)$ & 0.12 \\
\hline Paired men (n, \%) & $17(32.1)$ & $17(32.1)$ & $17(32.1)$ & $16(35.6)$ & \\
\hline Dim 1 & $56.94(7.10)$ & $57.76(8.19)$ & 60.71 (8.59) & $62.06(5.01)$ & 0.17 \\
\hline Dim 2 & $44.29(4.90)$ & $45.35(5.95)$ & $44.29(9.34)$ & $47.12(4.91)$ & 0.31 \\
\hline Dim 3 & $10.00(2.50)$ & $10.06(2.19)$ & $10.35(3.08)$ & $10.37(2.06)$ & 0.10 \\
\hline JSE total & $111.24(11.13)$ & 113.18 (12.68) & 115.35 (17.03) & $119.56(9.16)$ & 0.10 \\
\hline Unpaired women (n, \%) & $15(78.9)$ & $15(78.9)$ & $24(70.6)$ & $28(76.7)$ & \\
\hline Dim 1 & $62.27(4.33)$ & $61.47(3.52)$ & $62.83(7.14)$ & $62.86(7.07)$ & 0.20 \\
\hline Dim 2 & $50.00(3.29)$ & $49.73(4.57)$ & $47.42(8.68)$ & $49.29(4.17)$ & 0.94 \\
\hline Dim 3 & $11.87(1.96)$ & $11.67(1.95)$ & $11.42(3.22)$ & $12.82(1.02)$ & 0.29 \\
\hline JSE total & $124.13(7.73)$ & $122.87(6.58)$ & 121.67 (14.96) & $124.96(9.74)$ & 0.69 \\
\hline Unpaired men (n, \%) & $4(21.1)$ & $4(21.1)$ & $10(29.1)$ & $10(23.3)$ & \\
\hline Dim 1 & $62.50(5.32)$ & $64.75(3.95)$ & $60.20(7.57)$ & $57.50(8.06)$ & 0.40 \\
\hline Dim 2 & $46.00(4.00)$ & $43.00(16.67)$ & $46.10(7.53)$ & 45.60 (5.38) & 0.79 \\
\hline Dim 3 & $10.50(1.91)$ & $10.00(3.91)$ & $11.30(2.00)$ & $11.60(0.84)$ & 0.79 \\
\hline JSE total & $119.00(9.76)$ & $117.75(24.06)$ & $117.60(15.00)$ & $114.70(11.25)$ & 0.66 \\
\hline
\end{tabular}

C2, cohort 2; Dim, dimension; JSE-HP, jefferson scale of empathy-professional version; UFV, francisco de vitoria university.

only two European countries: one university in Portugal (cross-sectional), five in another UK university (longitudinal). Also, they analysed 15 universities in the USA, 10 universities in Asia and 2 universities in Africa.

The cross-sectional study in a medical school in Portugal showed that the empathy measures of senioryear students were higher than the scores of those from the first-year students. ${ }^{51}$ A longitudinal study from the UK showed that neither men nor women showed any change in cognitive empathy during the course. Women were more empathetic than men and men's affective empathy declined slightly, while women's affective empathy showed no change. Although statistically significant, the size was low. Neither men nor women appear to become meaningfully less empathetic during their medical education. ${ }^{52}$

Our results complement these studies and it seems to support the idea that, at least in the European setting, empathy does not diminish during the medical career. However, a recent study from Switzerland showed that empathy remains stable in most medical students but declines in some students. It suggests that some personality traits (openness) as well as patient-oriented motives for studying medicine were associated with higher and stable empathy. ${ }^{53}$

Besides, results from studies which use different instruments to analyse medical students' empathy, as IRI and
JSE, should be compared cautiously. Both scales measure different but related constructs. ${ }^{43}$ It might be appropriate to use both instruments or even use other scales that measure empathy from real or simulated patients ${ }^{46-48}$ in future studies.

We cannot establish a cause-effect relationship as our study lacks a control group, and all the possible confusion bias factors which may be influencing the results have not been isolated. However, it may help to acquire insight for asking questions and suggesting hypotheses. One question may be what sort of interventions are associated to better empathy outcomes. A second one could be whether the effects of these interventions are maintained in the long term, but actually little is known about it. ${ }^{54}$ Kataoka et a $l^{55}$ observed an improvement in the empathy of first-year medical students in Japan after an intervention was developed based on a communicative skills programme. They monitored this cohort of students and observed that the improvement in empathy did not last over time. They concluded that activities to improve empathy are necessary throughout the entire degree programme.

This study stresses the question about what variables are associated with better or worse outcomes. The empathy scores of UFV students seem higher than those reported in other countries ${ }^{3132}$ and in our environment, ${ }^{36}$ although these populations are not fully comparable with ours and 
we have not analysed these differences statistically. We may ask if it may be due to some of our 4-year educational pillars: a medical humanities pathway and a standardised patient-based programme on clinical communication and relationship.

Empathy training interventions may be a possible factor among others. Intervention length, scope of empathy measured or the kind of tool used are important variables. ${ }^{54}$ For instance, in two systematic reviews performed by the Best Evidence Medical Education, ${ }^{56}{ }^{57}$ the benefits of early clinical immersion at different levels are highlighted. On the affective level, early clinical immersion promotes empathetic attitudes in students towards the patients, reduces stress during clinical appointments, and enhances the awareness of the students' own feelings and reactions. As we have described, our personcentred curriculum has many kinds of interventions to promote empathy since first to last year. The Carnegie Foundation ${ }^{58}$ established the integration of theoretical knowledge into clinical experience from the start of the degree among its most important lines of work. The General Medical Council of the $\mathrm{UK}^{59}$ prefers a vertical integration of different types of practical experience over time. This idea attempts to break down the traditional division between preclinical and clinical courses (Flexner Academical Model).

Another variable to be considered is the criteria for admission. ${ }^{60}$ At our school, $20 \%$ of the admission score depends on the results of a personality, intelligence and psychopathological test to which candidates are submitted. Therefore, there is a possible selection bias towards students with a more humanistic and empathic profile. Stern $e t a l^{61}$ did not find a link between academic performance, used by the medical faculties for student access, and students' future professional behaviour. They believe, however, that certain humanistic personal qualities, such as empathy, could be an influence. In this case, Hojat et a $t^{404962}$ maintain that the personality and empathy questionnaires as well as personal interviews could be a useful extra element to consider in the selection process of the best students who wish to study at faculties of medicine. This should undoubtedly be a variable to consider in future studies.

A systematic review explored this question, but only a small number of possible influential factors were investigated in each publication reviewed. ${ }^{29}$ In this review, gender and age did not yield consistent results, but those students who selected patient-oriented specialties had higher empathy scores. Some studies selected in this systematic review found out that distress (for instance, burnout or a low sense of well-being) was associated to a decrease of empathy. Hidden curriculum could play a role: mistreatment, confrontation with clinical reality (illness, suffering, death), social support problems or an excessive workload. It suggests that not only educational interventions may play a role in empathy trajectory, but other factors should be taken in mind in order to design future studies.

\section{CONCLUSION}

The empathy of medical students at our school did not decline along grade years. In fact, it slightly improved in women, due to the cognitive dimension. Our institution makes a special effort in teaching empathy. This paper contributes to enlarge data from European area, where studies are scarce. It supports the idea that there may be global geo-sociocultural differences, however more studies comparing different school settings are needed to know what variables are associated with better results.

Acknowledgements The authors are grateful for the cooperation of the students and professors of Universidad Francisco de Vitoria, without whom this work would never have seen the light of day. They are also grateful to the Deanship of the School of Medicine for their humanistic outlook on teaching. We would like to thank Editage (www.editage.com) for English language editing.

Contributors All authors contributed to the study conception and design. Material preparation, data collection and analysis were performed by JMB, DM and FC. FC and SA led the person-centred medical curriculum. MP made substantial contributions to interpretation of data. The first draft of the manuscript was written by JMB and DM, and all authors commented on previous versions of the manuscript. All authors read and approved the final manuscript.

Funding The authors have not declared a specific grant for this research from any funding agency in the public, commercial or not-for-profit sectors.

Competing interests None declared.

Patient and public involvement Patients and/or the public were not involved in the design, or conduct, or reporting, or dissemination plans of this research.

Patient consent for publication Informed consent was obtained from all individual participants included in the study.

Ethics approval This study was performed in line with the principles of the Declaration of Helsinki. All the questionnaires were anonymous, by use of codes, with the aim of adhering to international data protection laws, such as the current Spanish regulation (Organic Law 3/2018, of 5 December, regarding the Protection of Personal Data and guarantee of digital rights, BOE 294 of 6/12/2018). When students voluntarily accept it, some data had a numerical identification code to make possible analysis of paired student cohorts without compromising anonymity. The study received the approval of the Ethics Committee of the Francisco de Vitoria University (Number/ID: 09/2017). Participation was voluntary and independent of students' academic results.

Provenance and peer review Not commissioned; externally peer reviewed.

Data availability statement Data are available upon reasonable request.

Open access This is an open access article distributed in accordance with the Creative Commons Attribution Non Commercial (CC BY-NC 4.0) license, which permits others to distribute, remix, adapt, build upon this work non-commercially, and license their derivative works on different terms, provided the original work is properly cited, appropriate credit is given, any changes made indicated, and the use is non-commercial. See: http://creativecommons.org/licenses/by-nc/4.0/.

ORCID iD

Diana Monge http://orcid.org/0000-0002-3593-1820

\section{REFERENCES}

1 Kim SS, Kaplowitz S, Johnston MV. The effects of physician empathy on patient satisfaction and compliance. Eval Health Prof 2004;27:237-51.

2 Zachariae R, Pedersen CG, Jensen AB, et al. Association of perceived physician communication style with patient satisfaction, distress, cancer-related self-efficacy, and perceived control over the disease. Br J Cancer 2003;88:658-65.

3 Pollak KI, Alexander SC, Tulsky JA, et al. Physician empathy and listening: associations with patient satisfaction and autonomy. J Am Board Fam Med 2011;24:665-72.

4 Attar HS, Chandramani S. Impact of physician empathy on migraine disability and migraineur compliance. Ann Indian Acad Neurol 2012;15:89-94. 
5 Zolnierek KBH, Dimatteo MR. Physician communication and patient adherence to treatment: a meta-analysis. Med Care 2009;47:826-34.

6 DiMatteo MR, Sherbourne CD, Hays RD, et al. Physicians characteristics influence patients' adherence to medical treatment: results from the medical outcomes study. Health Psychol 1993;12:93-102.

7 Del Canale S, Louis DZ, Maio V, et al. The relationship between physician empathy and disease complications: an empirical study of primary care physicians and their diabetic patients in Parma, Italy. Acad Med 2012;87:1243-9.

8 Hojat M, Louis DZ, Markham FW, et al. Physicians' empathy and clinical outcomes for diabetic patients. Academic Medicine 2011;86:359-64.

9 Ogle J, Bushnell JA, Caputi P. Empathy is related to clinical competence in medical care. Med Educ 2013;47:824-31.

10 Stepien KA, Baernstein A. Educating for empathy. J Gen Intern Med 2006;21:524-30.

11 Coulehan J, Platt F, Egener B. Let Me See If I Have This Right : Words That Help Build Empathy. Ann Intern Med Published Online First 2001.

12 San-Martín M, Roig-Carrera H, Villalonga-Vadell RM, et al. [Empathy, inter-professional collaboration, and lifelong medical learning in Spanish and Latin-American physicians-in-training who start their postgraduate training in hospitals in Spain. Preliminary outcomes]. Aten Primaria 2017:49:6-12.

13 Shanafelt TD, West C, Zhao X, et al. Relationship between increased personal well-being and enhanced empathy among internal medicine residents. J Gen Intern Med 2005;20:559-64.

14 Kelm Z, Womer J, Walter JK, et al. Interventions to cultivate physician empathy: a systematic review. BMC Med Educ 2014;14:219.

15 Shamasundar C. Understanding empathy and related phenomena. Am J Psychother 1999;53:232-45.

16 Yuguero O, Ramon Marsal J, Esquerda M, et al. Association between low empathy and high burnout among primary care physicians and nurses in Lleida, Spain. Eur J Gen Pract 2017;23:4-10.

17 Lamothe M, Boujut E, Zenasni F, et al. To be or not to be empathic: the combined role of empathic concern and perspective taking in understanding burnout in general practice. BMC Fam Pract 2014;15:15.

18 Sullivan P. Pay more attention to your own health, physicians warned. CMAJ 1990;142:1309-10.

19 Hafferty FW, Franks R. The hidden curriculum, ethics teaching, and the structure of medical education. Acad Med 1994;69:861-71.

20 Levinson W, Roter DL, Mullooly JP, et al. Physician-Patient communication. The relationship with malpractice claims among primary care physicians and surgeons. JAMA 1997;277:553-9.

21 Moore AR. Medical humanities - a new medical adventure. N Engl J Med 1976;295:1479-80.

22 Thomas MR, Dyrbye LN, Huntington JL, et al. How do distress and well-being relate to medical student empathy? A multicenter study. $J$ Gen Intern Med 2007;22:177-83.

23 Paro HBMS, Silveira PSP, Perotta B, et al. Empathy among medical students: is there a relation with quality of life and burnout? PLoS One 2014;9:e94133.

24 Hojat M, Gonnella JS, Mangione S, et al. Empathy in medical students as related to academic performance, clinical competence and gender. Med Educ 2002;36:522-7.

25 Colliver JA, Willis MS, Robbs RS, et al. Assessment of empathy in a Standardized-Patient examination. Teach Learn Med 1998;10:8-11.

26 Hojat M, Vergare MJ, Maxwell K, et al. The devil is in the third year: a longitudinal study of erosion of empathy in medical school. Acad Med 2009;84:1182-91.

27 Chen D, Lew R, Hershman W, et al. A cross-sectional measurement of medical student empathy. J Gen Intern Med 2007;22:1434-8.

28 Chen DCR, Kirshenbaum DS, Yan J, et al. Characterizing changes in student empathy throughout medical school. Med Teach 2012;34:305-11.

29 Neumann M, Edelhäuser F, Tauschel D, et al. Empathy decline and its reasons: a systematic review of studies with medical students and residents. Acad Med 2011;86:996-1009.

30 Hojat M, Shannon SC, DeSantis J, et al. Does empathy decline in the clinical phase of medical education? A nationwide, multi-institutional, cross-sectional study of students at DO-Granting medical schools. Acad Med 2020;95:911-8.

31 Roff S. Reconsidering the "decline" of medical student empathy as reported in studies using the Jefferson Scale of Physician EmpathyStudent version (JSPE-S). Med Teach 2015;37:783-6.

32 Ferreira-Valente A, Monteiro JS, Barbosa RM, et al. Clarifying changes in student empathy throughout medical school: a scoping review. Adv Health Sci Educ Theory Pract 2017;22:1293-313.
33 Spatoula V, Panagopoulou E, Montgomery A. Does empathy change during undergraduate medical education? - A meta-analysis. Med Teach 2019;41:895-904.

34 Ponnamperuma G, Yeo SP, Samarasekera DD. Is empathy change in medical school geo-socioculturally influenced? Med Educ 2019;53:655-65.

35 Alcorta-Garza A, San-Martín M, Delgado-Bolton R, et al. Crossvalidation of the Spanish HP-version of the Jefferson scale of empathy confirmed with some cross-cultural differences. Front Psychol 2016;7:1002.

36 Ferreira-Valente A, Costa P, Elorduy M, et al. Psychometric properties of the Spanish version of the Jefferson scale of empathy: making sense of the total score through a second order confirmatory factor analysis. BMC Med Educ 2016;16:242.

37 Blanco JM, Caballero F, García FJ, et al. Validation of the Jefferson scale of physician empathy in Spanish medical students who participated in an early clerkship immersion programme. BMC Med Educ 2018;18:209.

38 Edwards AL. The social desirability variable in personality assessment and research. Ft Worth, TX, US: Dryden Press, 1957

39 Hojat M, Zuckerman M, Magee M, et al. Empathy in medical students as related to specialty interest, personality, and perceptions of mother and father. Pers Individ Dif 2005;39:1205-15.

40 Hojat M, DeSantis J, Shannon SC, et al. The Jefferson scale of empathy: a nationwide study of measurement properties, underlying components, latent variable structure, and national norms in medical students. Adv Health Sci Educ Theory Pract 2018;23:899-920.

41 International Alliance of Patients' Organizations. International college of person-centered medicine, 2019. Available: https://www.iapo.org. uk/international-college-person-centered-medicine

42 Jefferson Scale of Empathy. Asano-gonnella center for research in medical education \& health care, 2020. Available: https://www. jefferson.edu/academics/colleges-schools-institutes/skmc/research/ research-medical-education/jefferson-scale-of-empathy.html

43 Costa P, de Carvalho-Filho MA, Schweller M, et al. Measuring medical students' empathy: exploring the underlying constructs of and associations between two widely used self-report instruments in five countries. Acad Med 2017;92:860-7.

44 Hojat M, Mangione S, Nasca TJ, et al. The Jefferson scale of physician empathy: development and preliminary psychometric data. Educ Psychol Meas 2001;61:349-65.

45 Hojat M, Gonnella JS, Nasca TJ, et al. Physician empathy: definition, components, measurement, and relationship to gender and specialty. Am J Psychiatry 2002;159:1563-9.

46 Glaser KM, Markham FW, Adler HM, et al. Relationships between scores on the Jefferson scale of physician empathy, patient perceptions of physician empathy, and humanistic approaches to patient care: a validity study. Med Sci Monit 2007;13:CR291-4

47 Blanco Canseco JM, Valcárcel Sierra C, Guerra Jiménez MDC, et al. [Clinical empathy among family and community medicine residents and tutors. The view of physicians and patients]. Aten Primaria 2020;52:185-192.

48 Berg K, Majdan JF, Berg D, et al. A comparison of medical students' self-reported empathy with simulated patients' assessments of the students' empathy. Med Teach 2011;33:388-91.

49 Hojat M. Empathy in health professions education and patient care. Cham: Springer International Publishing, 2016.

50 Assing Hvidt E, Søndergaard J, Hvidt NC, et al. Development in Danish medical students' empathy: study protocol of a crosssectional and longitudinal mixed-methods study. BMC Med Educ 2020;20:54

51 Magalhães E, Salgueira AP, Costa $P$, et al. Empathy in senior year and first year medical students: a cross-sectional study. BMC Med Educ 2011;11:52.

52 Quince TA, Parker RA, Wood DF, et al. Stability of empathy among undergraduate medical students: a longitudinal study at one UK medical school. BMC Med Educ 2011;11:90.

53 Piumatti G, Abbiati M, Baroffio A, et al. Empathy trajectories throughout medical school: relationships with personality and motives for studying medicine. Adv Health Sci Educ Theory Pract 2020;25:1227-42.

54 Teding van Berkhout E, van Berkhout ET, Malouff JM. The efficacy of empathy training: a meta-analysis of randomized controlled trials. $J$ Couns Psychol 2016;63:32-41.

55 Kataoka $\mathrm{H}$, Iwase $\mathrm{T}$, Ogawa $\mathrm{H}$, et al. Can communication skills training improve empathy? A six-year longitudinal study of medical students in Japan. Med Teach 2019;41:195-200.

56 Dornan T, Littlewood S, Margolis SA, et al. How can experience in clinical and community settings contribute to early medical education? A BEME systematic review. Med Teach 2006;28:3-18. 
57 Yardley S, Littlewood S, Margolis SA, et al. What has changed in the evidence for early experience? update of a BEME systematic review. Med Teach 2010;32:740-6.

58 Cooke M, Irby D, O'Brien B. Educating physicians: a call for reform of medical school and residency. Hoboken: John Wiley \& Sons, 2010.

59 Dornan T, Littlewood S, Margolis SA, et al. How can experience in clinical and community settings contribute to early medical education? A BEME systematic review. Med Teach 2006;28:3-18.
60 O'Sullivan DM, Moran J, Corcoran P, et al. Medical school selection criteria as predictors of medical student empathy: a cross-sectional study of medical students, Ireland. BMJ Open 2017;7:e016076.

61 Stern DT, Frohna AZ, Gruppen LD. The prediction of professional behaviour. Med Educ 2005;39:75-82.

62 Hojat M, Gonnella JS. Eleven years of data on the Jefferson scale of empathy-medical student version (JSE-S): proxy norm data and tentative cutoff scores. Med Princ Pract 2015;24:344-50. 